Capítulo 3

\title{
LOS ESTUDIOS SOBRE LOS PÚBLICOS DE ARTES
}

\author{
Vanina Papalini y Marina Moguillansky
}

All in all, the creative act is not performed by the artist alone; the spectator brings the work in contact with the external world by deciphering and interpreting its inner qualification and thus adds his contribution to the creative act.

“The Creative Act", Marcel Duchamp, Houston, Texas, abril de 1957.

\section{Introducción}

En este capítulo nos ocuparemos de revisar los estudios centrados en la recepción de las artes, incluyendo a las artes plásticas y los museos en general, el cine, la danza, la música, el teatro y los festivales. Quizá por tratarse de artes cuya recepción abre una incierta pregunta sobre el mundo, como expresa Duchamp, el involucramiento del público, como partícipe de los sentidos de la obra, no está en discusión. A diferencia de lo que ocurre con los medios masivos o con las obras literarias, los anclajes en la recepción de las obras artísticas nunca fueron seguros; existe al respecto una vasta literatura sobre el tema. Los antecedentes teóricos sobre recepción de artes pueden volverse una genealogía infinita que involucre desde el concepto de aura de Walter Benjamin a la comprensión privilegiada que Friedrich Schleiemacher asigna al intérprete.

La primera tensión que se manifiesta en torno a los objetos de estudio que proponemos en este capítulo no tiene que ver, por tanto, con la "actividad" -indiscutida- del receptor sino por sus condiciones, consideradas cuando la recepción deja de ser concebida en términos individuales. La noción de "públicos" ampara las dos posibilidades: puede referirse a un 
conjunto de individuos reunidos en torno a una afición común, o a un grupo que comparte un sistema valorativo y ciertos gustos modelados en relación a sus contextos sociales.

En este sentido, la recepción pensada desde las ciencias sociales normalmente se refiere a los públicos entendidos como un colectivo. Nociones tales como "tradición", "clase", "habitus" o "identidad" reinsertan al receptor en una trama social, cultural, histórica o generacional en donde parecen encontrarse las claves de sus prácticas culturales, sus gustos y sus matrices de interpretación. Dado el enfoque con el que realizamos este relevamiento, "público" es definido siempre como una categoría social.

\section{Acerca del objeto}

La segunda tensión que observamos tiene que ver con el lugar que se les asigna a estas artes en la cultura. Las mismas prácticas culturales pueden ser objeto de tratamiento tanto en el campo artístico como en el campo de las culturas populares. Entre ambos abordajes hay una ligera línea divisoria; mientras unos enfatizan el análisis de las condiciones de producción y la obra, los otros se concentran especialmente en las condiciones de recepción y los públicos empíricos. Eventualmente el primer enfoque puede interesarse en el receptor modelo -que emerge de la propia concepción de la obra y sus realizadores- y el segundo por las condiciones de producción y la tradición en la que se inserta la obra, pero solo en casos excepcionales las dos miradas se complementan. Dado que esta investigación concierne a los estudios sobre públicos, hemos dejado fuera de nuestra indagación las aproximaciones centradas en la obra.

Las tensiones entre perspectivas se hacen evidentes en la disputa por la legitimidad de una producción o práctica cultural. Si bien la investigación sobre los públicos dominante en ciencias sociales se desentiende de la calificación de la obra, la cuestión de su legitimidad ingresa por una entrada lateral: se desplaza a otra dimensión (por ejemplo, política: intervenciones plásticas urbanas e impugnación social), o se asume su "ilegitimidad" dentro del campo artístico y se la estudia como tal (como en el caso de la cumbia villera y marginalidad). 
La calificación de "subalterno" implica otro matiz. En este caso, la perspectiva de "culturas populares" asume implícitamente la existencia de una cultura "no popular" (¿culta?) y abandona la discusión sobre el carácter artístico de estas producciones. Así, la concepción de la práctica artística define de alguna manera el abordaje. Todo aquello que ingresa en la determinación de "culturas populares" es objeto de las ciencias sociales, mientras que lo que se define como "arte" pasa al terreno de las disciplinas artísticas, la semiótica del arte o las humanidades, y muy pocas veces es objeto de la consideración sociológica, salvo en términos cuantitativos -cantidad de espectadores, por ejemplo, o en caracterizaciones sociodemográficas de los públicos-.

Las distintas prácticas artísticas se distribuyen de manera diferente en relación a las definiciones de "Arte" y "Cultura Popular". Mientras que las artes plásticas se sitúan siempre del lado de las bellas artes (con la única excepción del graffiti), la música se encabalga en ambas categorías. La plasticidad y ubicuidad de la práctica y la diversidad de su público hacen que su clasificación como arte o como cultura de masas/culturas populares se opere en virtud del género (ópera y música de cámara versus rock y cumbia, por ejemplo). En el caso de las artes plásticas y visuales, su apertura al gran público pasa por la democratización del acceso -vinculada a la desmuseificación del museo o a su exhibición en otros espacios públicos menos marcados por distinciones simbólicas-. Las investigaciones halladas sobre estas artes se refieren casi exclusivamente al espacio y su público; son minoritarias las que combinan de manera eficaz un trabajo sobre los públicos y sobre las obras.

El caso de las artes escénicas amerita una diferenciación entre teatro y danza. En el teatro se expresa ostensiblemente una segunda forma de decidir la ubicación de la práctica artística: ya no se trata principalmente del género, sino de su circulación y éxito de taquilla. Se lo considera una práctica creativa, asociadas al virtuosismo y la experimentación, cuando no transita por los circuitos comerciales - condescendientes con las demandas de mercado-, sino por circuitos independientes, off o under. Así, podríamos imaginar una tenue línea que separa el teatro-arte del teatro-espectáculo, siendo este último un objeto relegado, una de las artes menos atendida en términos de estudios cualitativos de recepción.

Es interesante la transformación del lugar ocupado por la danza. En parte por su imbricación cada vez mayor con el teatro, dando lugar a fu- 
siones del tipo danza-teatro, en parte, porque está intrínsecamente asociada a la música, la danza se adhiere a otras artes o se desdibuja en festivales. Así, las danzas populares - por ejemplo el folclore-aparecen en eventos generales, mientras que el ballet sigue ocupando el espacio reservado para las artes, prioritariamente teatros. La democratización del acceso a las artes, en el caso de la danza implica ciertos desplazamientos, tales como la exhibición del ballet en espacios públicos y el proceso de profesionalización de danzas populares, como el tango, que comparte los escenarios de las artes "cultas" al mismo tiempo que se ofrece como espectáculo, en la lógica de lo masivo/comercial (Carozzi, 2011: 238-240).

En el caso del cine, la tensión principal se delinea entre el circuito comercial de los complejos multipantalla, dominados por las películas hollywoodenses, y el circuito del cine independiente o artístico, que tiene lugar en los festivales de cine y en las salas de cine de arte y ensayo. Ocurre aquí algo semejante a lo que se observa en el teatro: hay públicos "expertos" o "de culto" que transitan por circuitos no comerciales (ciclos especiales, salas o cineclubes, festivales independientes). La clasificación que diferencia el cine-arte del cine de entretenimiento depende de la crítica en gran medida; la marca de autor -el director, en este caso- sigue teniendo importancia. Es menos importante la diferencia que proponen los géneros, puesto que todos ellos pueden abrirse a la experimentación (como vemos que sucede con la animación o el spaghetti-western).

Estas observaciones tienen consecuencias a la hora de emprender una investigación: cada disciplina expresa cierta tendencia a privilegiar un aspecto de la cuestión. También así se entiende la relevancia que cobran los lugares de presentación o puesta en escena, dado que determinan en gran medida el tipo de público y el tipo de fruición: museos, salas teatrales comerciales o circuitos independientes y alternativos, cines, videoclubes $-\mathrm{O}$ proyección doméstica-, festivales, espacios públicos, algo dicen que habla no solo del público, sino de la obra misma e incluso, de su calificación dentro o fuera del sistema del arte. Siguiendo este mismo argumento, cuando estas prácticas son parte de la programación de los medios masivos, quedan referidas al medio mismo y no son ya objeto de este capítulo.

Frente a este panorama, hemos optado por organizar este relevamiento en torno a las distintas prácticas artísticas, asumiendo que cada una tiene características particulares y propone distintas formas de recep- 
ción. En esta delimitación, tomamos como fuente el sistema de estadísticas de la UNESCO, con algunas variaciones y asociaciones que emergieron a partir de la consideración del material revisado. Identificamos: 1) Museos, artes plásticas y visuales; 2) Cine; 3) Danza y festivales; 4) Teatro; 5) Música y baile. ${ }^{1}$ Aquí es necesaria una consideración más: "danza y festivales" no se refiere estrictamente a las danzas escénicas, es decir, aquellas que están montadas de manera tal que no se habilite la participación externa pues, como veremos en el caso de los festivales o danzas callejeras, en muchos casos los públicos no son meros espectadores. ${ }^{2}$ Por esa razón la hemos desagregado de la clasificación de "artes escénicas"; no obstante, en este segmento ponemos el énfasis en la danza misma y no en el baile que aparece en la categoría 5. La definición de "danza" se diferencia del "baile" por el acento puesto en la coreografía, mientras que el segundo tiene como dato crucial la música y tanto puede referirse a un espacio específico preparado para bailar -donde la música aparece como complemento necesario- como las prácticas que se realizan a partir de una escena en la que la ejecución musical en vivo y el baile mismo están en un plano de igualdad -el baile de cuarteto, por ejemplo, que es al mismo tiempo "baile" y "recital".

El relevamiento abarca la producción científica argentina del período 2000-2012. Sin embargo, los grupos de investigación de mayor tradición se conformaron unos diez años antes; por lo tanto, hemos hecho referencia a algunos aportes previos que, creemos, ayudan a entender la configuración de la investigación reciente. Los estudios que llamamos "pioneros" y la investigación actual, quedan divididos por la línea secante del período de la dictadura militar. Aunque hay algo de investigación en el período, las condiciones de censura y las matrices de pensamiento impuestas estable-

1 El Marco de Estadísticas Culturales de la Unesco establece 10 categorías: 1) Patrimonio cultural; 2) Materiales impresos y literatura; 3) Música; 4) Artes escénicas; 5) Artes plásticas y visuales; 6) Cine; 7) Radio y televisión; 8) Actividades socioculturales; 9) Juegos y deportes; 10) Naturaleza y medio ambiente. En este volumen, abordamos desde la segunda a la séptima e incluimos el uso de tecnologías que no está contemplado por la UNESCO. En este capítulo en particular, nos abocamos a las categorías 3, 4, 5 y 6, con algunas especificaciones relativas a los estudios existentes en la Argentina.

2 Seguimos aquí la clasificación de Kaeppler, que distingue danzas escénicas de danzas participativas (Kaeppler, 1978 en Carozzi, 2011: 14). 
cen discontinuidades y silencios que no pueden soslayarse; es por eso que preferimos evitar el análisis de la producción del período, ya que cualquier conclusión estaría sesgada por las condiciones para la producción del conocimiento y la expresión artística impuestas por un gobierno dictatorial.

\section{Antecedentes teóricos generales}

Entre los antecedentes teóricos que podrían ser marcos de la investigación sobre públicos de artes, identificamos estas cuatro grandes perspectivas generales:

Marxista. Se trata de una perspectiva que encuentra en Arnold Hauser uno de sus principales referentes. Sus libros Historia social de la literatura y el arte (1969 [1951]); Teorías del arte (1982 [1958]) y Sociología del arte (1975) son claves en la conformación de la sociología del arte moderna como un subcampo especial. La explicación materialista del arte -sumamente cuestionada- llevó a la ruptura con las interpretaciones idealizadas y permitió establecer las relaciones entre el acto creativo y sus contextos de emergencia y de circulación. Esta sobredeterminación del arte por lo social y la escasa consideración de la obra fueron objeto de numerosas críticas, entre ellas la de Ernst Gombrich.

Sociología histórica comparativa. La aproximación de Pierre Francastel, centrada en la obra Pintura y sociedad (1960 [1951]), enfatiza el carácter específico del lenguaje artístico. Tomando como punto de partida la obra de arte, se propone caracterizar su época y su contexto de creación, integrando de esa manera la consideración de las dimensiones políticas y sociales y prestando especial atención a las variaciones del arte a lo largo del tiempo. Sus estudios, a veces criticados por excesivamente formalistas, se valen de las nociones que aporta la semiología estructuralista.

Hermenéutica. La sistematización más importante en cuanto al tratamiento de la recepción artística es la de Hans-Georg Gadamer en Verdady método (1977 [1960]). Retomando las teorías algo psicologistas de Schleiermacher, Gadamer propone la relación de la obra como parte de una tradición, con su propio contexto y su propia historia, interrogada desde el presente por el receptor. Así, toda obra encuentra distintos sentidos en las distintas fusiones horizónticas (el horizonte de sentido de la 
obra misma y el del presente del intérprete). Aunque la comprensión de sentido es epocal, histórica; la obra (y no su autor) es una de las voces en un diálogo, por eso, la comprensión estética que resulta de una experiencia estética en presente informada por la tradición, produce una síntesis interpretativa. La crítica que Terry Eagleton (1998) lanza contra la hermenéutica alude a su conservadurismo: desde esta perspectiva, la fuerza atribuida a la tradición opaca toda valoración de las vanguardias.

Bourdeana. Esta perspectiva fundada por los trabajos de Pierre Bourdieu y Alain Darbel en El amor al arte. Los museos europeos y su público (1966), ${ }^{3}$ luego continuada por Bourdieu en numerosos trabajos de los cuales los más célebres son La Distinction (1979) y Les règles de l'art (1992). Esta tradición investigativa ha tenido gran impacto en la sociología de la cultura y en la antropología social, y es actualmente el paradigma dominante. Las tesis centrales de Bourdieu sobre el arte y las prácticas de recepción sostienen que la competencia artística depende de la familiaridad con los códigos del arte, es decir, con el conocimiento de la historia, los géneros y los estilos artísticos; estas competencias son capitales culturales adquiridos por la instrucción escolar y por la socialización familiar en los sectores cultivados. Algunos conceptos clave de la obra bourdeana se insertan en las investigaciones actuales de los públicos de arte: distinción, habitus, campo artístico, capital cultural y simbólico, ortodoxia y heterodoxia, entre otros.

Estudios culturales. Esta corriente ofrece una relectura de las matrices de interpretación, las prácticas culturales y los sistemas axiológicos que, siguiendo una concepción gramsciana, se relacionan con las clases sociales como portadoras de una cultura definida por su subalternidad en relación a la cultura dominante en términos de legitimidad y circulación. Estas

3 Allí investigaron la composición social, profesional y educativa del público de 21 museos europeos, analizando las variaciones en sus prácticas y gustos artísticos. La tesis central que defienden es que el gusto artístico no es innato sino fruto de la instrucción escolar. El acceso al arte es privilegio de la "clase culta", pero esta restricción no se basa en barreras materiales sino simbólicas que se manifiestan en la distribución desigual de la aspiración cultural, de las competencias artísticas y de la preparación actitudinal. De esta manera, la exclusión de buena parte del público con respecto a la apropiación del arte se ve legitimada como auto-exclusión. De dicha obra proviene la distinción entre "placer estético", "buena voluntad cultural" y "obligación", como posibles experiencias de los visitantes de museo. 
culturas no son imitativas sino que expresan capacidad de creación, de negociación e incluso de impugnación (Hall, 1980). En este sentido, se reivindica la agencia del espectador/consumidor de cultura para producir sentido e interpretar los mensajes. Para los Estudios Culturales, la recepción artística es una práctica sociocultural, imbricada en relaciones de poder, que debe ser leída en su contexto político, social y económico. En cuanto a los estudios sobre consumo y recepción de artes, uno de los textos más originales, precursor de una línea de investigación, ha sido The Sociology of Rock, de Simon Frith, 1978.

\section{Investigaciones en la Argentina, 2000-2012}

\section{Estudios de público de museos y artes plásticas}

El área de la investigación del público de las artes plásticas en general y de los museos en particular cuenta con extensos y relevantes antecedentes a nivel internacional. Distinguimos las investigaciones sociales cualitativas sobre el público de museos y de arte, que en términos generales se han pensado como trabajos sobre el consumo cultural, de los llamados "estudios de público" o "visitors studies" que son en general indagaciones puntuales sobre una exposición o una institución, de orientación más bien cuantitativista. ${ }^{4}$ En este apartado, nos concentraremos en el primer tipo de investigaciones, si bien señalaremos también el desarrollo en la Argentina de algunas del segundo tipo. Existen además una serie de trabajos que analizan a los museos en su rol educativo, que no se incluyen en este relevamiento. $^{5}$

En cuanto a la tradición sociológica y antropológica de investigaciones del público de museos, nos concentraremos en tres trabajos que han sido claves para configurar el área, teniendo en cuenta especialmente

4 Según Graciela Schmilchuk, "Las preguntas más usuales que se formulan han sido quiénes son los visitantes, cuáles regresan y cuáles no (frecuentación); cuál es la imagen del museo o de una exposición especial en algunos sectores sociales; cuál ha sido el éxito de la exposición en términos cuantitativos y cualitativos; qué y cuánto aprende la gente, o cuáles son los mensajes que se han logrado comunicar y por qué" (1996: 36).

5 Puede consultarse al respecto el trabajo de Florencia Puebla Antequera (2012). 
aquellos que tuvieron ecos y continuaciones en la Argentina. Por ello, nos referiremos brevemente a las investigaciones de Eliseo Verón y Martine Levasseur (1983) y de Néstor García Canclini (1987). Luego, describiremos los trabajos realizados en la Argentina sobre el público de museos y las artes plásticas, para finalmente señalar algunos rasgos característicos, en términos teóricos y metodológicos, del estado del arte en este subcampo.

El estudio fundacional de Bourdieu y Darbel El amor al arte. Los museos europeos y su público, de 1966, que mencionamos al comienzo, se convirtió pronto en una referencia obligada para los siguientes estudios de público de museos realizados desde las ciencias sociales. En diálogo con dicha obra, pero distanciándose de ella en aspectos muy relevantes, se produjo un hito para los estudios de público de museos. Nos referimos al trabajo que coordinó Eliseo Verón a comienzos de la década de 1980 en Francia, ${ }^{6}$ empleando una metodología que, a diferencia del trabajo de Bourdieu y Darbel, combinaba la semiótica y la etnografía para observar con detalle el comportamiento del público en relación con el recorrido propuesto por una exposición realizada en París. En esa ocasión, hicieron un análisis semiótico de la propuesta de la exposición, luego una observación etnográfica de los visitantes (atendiendo a los recorridos, secuencias, duración, omisiones, comentarios, gestos) y finalmente entrevistas con una muestra pequeña de asistentes de acuerdo a perfiles detectados durante la observación. Los principales hallazgos se publicaron en un libro que se tornaría clásico para los estudios de público (Verón y Levasseur, 1983). Los autores trabajaron con la idea de que "el comportamiento de la visita expresa el desfase entre la producción y el reconocimiento, que debe ser considerado como una negociación entre el discurso propuesto y las estrategias de apropiación del sujeto" (1983: 40). Asimismo, se propuso una tipología de los visitantes del museo, basaba en los comportamientos

6 Este trabajo surgió de una investigación empírica realizada en la exposición de fotografías "Vacances en France" organizada por el Centre Georges Pompidou, en la cual se observó el comportamiento de los visitantes, sus comentarios durante la experiencia, los recorridos y desplazamientos por el espacio expositivo y la distancia guardada con los objetos; se desarrollaron también entrevistas en profundidad con algunos de los visitantes. Los resultados de esta investigación fueron publicados en un libro (Verón y Levasseur, 1983). 
del público y en sus capitales culturales, según la cual habría "hormigas", "mariposas", "peces", y "langostas".

De manera simultánea, se desarrollaba en México el primer estudio importante sobre el público de museos de América Latina. Un equipo coordinado por Néstor García Canclini realizaba a comienzos de la década de 1980 una investigación que se inspiraba en la teoría de Bourdieu para estudiar al público de museos en perspectiva sociológica. La publicación de El público como propuesta. Cuatro estudios sociológicos en museos de arte confirmaba algunos de los postulados bourdeanos acerca de la forma en que las estructuras e instituciones sociales moldean los gustos, hábitos y creencias culturales de los públicos. Sin embargo, se pusieron también de relieve las especificidades del público de museos en México, llamando la atención sobre una relativamente mayor apertura de los sectores populares frente a las innovaciones. ${ }^{8}$ Los autores mostraban el predominio de procesos de recepción ritualizada de símbolos y nombres, en detrimento de la apropiación del arte.

En el ámbito de los "visitors studies", a nivel internacional, hubo un gran desarrollo y un giro en la orientación teórica a partir de fines del siglo XX. Este viraje fue correlativo a un cambio en las teorías museológicas, con la aparición de la Nueva Museología y la Museología Crítica. Ello supuso un cambio en los diseños institucionales y en la forma de pensar al visitante, al cual se pasó a concebir como sujeto activo que interpreta el recorrido a partir de sus propios repertorios culturales. La proliferación de los estudios de público, a nivel internacional y local, estuvo impulsada entre otros factores por la demanda de distintas instituciones que encargan estos trabajos con el objetivo de evaluarse y/o ajustar sus políticas culturales (Schmilchuk, 1996).

7 Este trabajo se difundió años después en la Argentina, en particular a partir de 1997, año en el que Verón dictó el seminario "Los espacios públicos de consumo cultural como medios de comunicación", durante un ciclo de conferencias organizado por la Universidad de Buenos Aires.

8 Contra lo que señalaban Bourdieu y Darbel para el público europeo, ya que según su perspectiva quienes menos dominan los códigos artísticos -las clases populares- son a su vez menos capaces de interpretar y por consiguiente de aceptar propuestas de vanguardia que rompen con dichos códigos. 
En la Argentina, el trabajo pionero en el área fue dirigido por Regina Gibaja y publicado como libro en 1964 por Eudeba, con el título El público de arte. El trabajo había sido encargado por el Instituto Torcuato di Tella al recientemente creado Instituto de Sociología de la Universidad de Buenos Aires, donde Gino Germani era la figura central. La investigación consistió en una encuesta aplicada a los visitantes de una exposición de arte, con una muestra sistemática al azar y utilizando un cuestionario que indagaba diversos aspectos sociodemográficos, educativos y profesionales, así como las actitudes y valoraciones de la cultura, el arte y los medios masivos de comunicación.

El desarrollo de los estudios de público de museos en la Argentina en general se basó en metodologías cuantitativas, casi siempre a partir de encuestas a los visitantes, siguiendo la línea marcada por el trabajo de Regina Gibaja, aunque en general sin su alcance y ambición teórica. Sin embargo, a partir de fines de la década de 1990 aparecieron algunas iniciativas novedosas que incorporaban nuevas perspectivas teóricas y metodológicas. En algunos espacios, se crearon observatorios y talleres permanentes destinados a monitorear el vínculo del museo con su público. Destacamos aquí dos núcleos importantes en este sentido: los trabajos en el Museo de Arte Popular José Hernández, en Buenos Aires y el Laboratorio de Estudios de Público del Museo de Antropología y la Universidad Nacional de Córdoba.

Los trabajos en el Museo Hernández fueron iniciados por Ana María Cousillas, quien creó un taller de estudios de público en dicho museo y desarrolló diversas investigaciones incorporando a la semiótica como herramienta de trabajo. Su trabajo se basó en entrevistas cualitativas y observaciones de los visitantes del museo; sus análisis ponen en relación la producción discursiva de los visitantes con los textos y las propuestas visuales de los museos. La autora afirma que el visitante tiene competencias semióticas aprendidas socialmente, mediante las cuales en cada visita construye una estrategia de recorrido, evoca sus experiencias pasadas y reacciona de distintas maneras (se identifica, se siente ajeno, se sorprende, ignora o rechaza) ante la propuesta del despliegue expositivo (Cousillas, 1997, 2001, 2003). La autora también coordinó una investigación que se basó en entrevistas a personas de clase media en la ciudad de Buenos Aires, consultadas acerca de sus hábitos de consumos culturales y sobre el lugar que 
ocupa el museo entre ellos. En este trabajo, se relevaron una serie de resistencias por parte del público potencial hacia los museos, considerados como espacios anticuados, aburridos y estáticos (Cousillas y otros, 1998). Otros trabajos realizados en el marco de este equipo son los de Mirta Bialogorski y Paola Fritz (Bialogorski y Fritz, 2011; Fritz y Bialogorski, 2012), también desde una perspectiva semiótica y antropológica que privilegia el análisis de las interpretaciones del patrimonio cultural.

El segundo núcleo de estudios sobre públicos se creó en la provincia de Córdoba a partir de un proyecto de investigación que comenzó en 1998 coordinado localmente por Mirta Bonnin Picart. Luego se instituyó un Laboratorio de Estudios de Público, radicado en el Museo de Antropología y con participación de la Universidad Nacional de Córdoba y de la Universidad Nacional de Río Cuarto, con financiamiento de la Agencia Española de Cooperación y Desarrollo (AECID). Dicho Laboratorio ha producido información descriptiva sobre los visitantes del museo, elaborando un registro sistemático de visitantes en 16 museos dependientes de la Universidad Nacional de Córdoba.

Más allá de la producción de dichos equipos de trabajo, encontramos algunos aportes de estudios de caso en distintos museos y sitios arqueológicos. La tesis de Puebla Antequera (2012) sobre el público del Museo del Área Fundacional de Mendoza resulta interesante e innovadora por su complejo dispositivo metodológico, en el que combina el análisis del guión del museo con encuestas, observaciones, entrevistas, mapas de significado personal y análisis del libro de visitas. En su trabajo, reconstruye la experiencia de los visitantes del museo, los caracteriza, elabora una tipología de patrones de recorrido e indaga en las interpretaciones que hace el público sobre la propuesta museística. Para ello Puebla se encarga de historizar los diversos enfoques que se han desarrollado en torno a los estudios de públicos en el campo de la museología.

Otros estudios se han dedicado a la relación del museo con la comunidad y la función política del museo como institución, reflexionando sobre las construcciones identitarias que promueve. En esta dirección, se destacan los trabajos de Rubens Bayardo (2001, 2004, 2007), en los cuales problematiza la actividad museística desde la perspectiva más amplia de las políticas culturales. También es relevante el aporte de María Eugenia Conforti (2012), que analiza la relación entre un museo y la 
comunidad, ${ }^{9}$ mostrando que el museo trabaja principalmente con un público "cautivo".

Por último, podemos señalar un núcleo de estudios que, tangencialmente, abordan la cuestión del consumo artístico en relación al coleccionismo de arte. En estas investigaciones convergen disciplinas como la Historia del Arte, la Sociología y la Antropología, con cruces e intercambios de herramientas conceptuales y metodológicas. El trabajo de Marisa Baldasarre, titulado Los dueños del arte (2006), resulta un hito fundamental. La autora estudia el coleccionismo en el período de formación del mercado artístico en Buenos Aires, en una reconstrucción histórica muy cuidadosa y teóricamente inspirada en conceptos de Pierre Bourdieu y Walter Benjamin. Su trabajo indaga las concepciones sobre el arte de los primeros coleccionistas, los criterios que rigieron la formación de sus colecciones y las maneras en las que previeron el pasaje de las mismas al dominio público a través de la institución del museo. Más recientemente Baldasarre y Silvia Dolinko han editado Travesías de la imagen (2011), un libro que reúne valiosos aportes sobre coleccionismo y consumo de artes visuales en diferentes provincias de la Argentina. Desde la sociología del arte, Mariana Cerviño $(2007,2011)$ ha estudiado los nuevos coleccionismos contemporáneos. ${ }^{10}$ Talia Bermejo en $E l$ precio de la belleza indaga el coleccionismo de arte entre 1920 y 1960 en la Argentina, deslindando los cambios en el significado de la compra de un objeto de arte, de acto estético a gesta patriótica y más recientemente a inversión financiera (Bermejo, 2014). La autora ha trabajado también sobre los coleccionistas de vanguardia destacando la multiplicación de roles que se combinaron en algunos personajes que fueron al mismo tiempo coleccionistas, artistas, gestores y empresarios, que generaron un tipo de consumo alternativo que rompía con los parámetros establecidos. Por su parte, Isabel

9 Se trata de la comunidad de Tres Arroyos en relación con el sitio arqueológico aledaño conocido como "Arroyo Seco 2" y con el Museo Municipal José A. Mulazzi.

10 La autora propone distinguir dos tipos de actores, por un lado un grupo reducido con más larga trayectoria y con participación institucional; por otro lado, los nuevos coleccionistas, provenientes de sectores medios altos, profesionales liberales, con menor capital económico, que se concentran en comprar obras de artistas argentinos jóvenes. Este fenómeno obedece tanto a estrategias de distinción -a través de un consumo sofisticado- como a estrategias de inversión. Los nuevos coleccionistas constituyen la principal demanda real en la comercialización del arte argentino contemporáneo. 
Plante (2013) ha rastreado la circulación de la obra de ciertos artistas latinoamericanos y argentinos por Europa.

En un balance sobre el estado de la cuestión, se observa que hubo múltiples iniciativas paralelas de investigaciones sobre el consumo de artes plásticas y sobre el público de museos que no han logrado continuidad, lo cual ya había sido señalado por balances previos como los de Bayardo y Wortman (2012) y Schmilchuk (2012), que lo atribuyen a la debilidad de los Estados y las políticas culturales en América Latina. En particular, los estudios de público de museos rara vez han abarcado a más de una institución y en general se han concentrado en describir los rasgos sociodemográficos de los visitantes. Aun así, estos trabajos hacen aportes relevantes y han contribuido a mostrar, entre otras cuestiones, que existe un desfasaje entre la propuesta de la institución (y/o los curadores), por un lado, y la interpretación efectiva que producen los visitantes. Los aprendizajes en el museo no son los que la institución pretende ofrecer, sino que corresponden a un currículum oculto (cómo recorrer una institución cultural, cómo comportarse, etcétera).

En cuanto a las orientaciones disciplinares y teóricas, se observa el predominio de trabajos que se basan en la sociología de la cultura y la antropología cultural, con la novedad de la incursión -más bien reciente- de la historia del arte en el área del consumo cultural. En efecto, los aportes de la historia del arte y de la sociología del arte, que se han ocupado indirectamente de la conformación de públicos de arte a partir de las nociones de circulación, coleccionismos y cultura visual, son originales en este sentido. De esta manera, Baldasarre, Bermejo, Dolinko y Cerviño han generado una serie de productivas investigaciones acerca de los orígenes, el devenir y la actualidad del mundo del arte en la Argentina en relación con los mercados internacionales. Estos trabajos contribuyen a develar ese mundo aurático mostrando la carnadura de sus actores, las estrategias sociales e institucionales y los procesos históricos que permiten comprender mejor su funcionamiento. Se deja de lado la perspectiva exclusivamente centrada en el "visitante de museo" para plantear la conformación histórica de los acervos museísticos, la cultura visual y de la red de instituciones y relaciones sociales e históricas.

Es notoria la convergencia teórica de las investigaciones, desde las distintas disciplinas, en torno a la obra de Pierre Bourdieu. La teoría de los 
campos, los conceptos de habitus y distinción, la mediación social de los gustos artísticos, forman parte del repertorio que articula los estudios aquí relevados. La sociología cultural de Bourdieu parece haberse convertido en el paradigma dominante, sin embargo sus metodologías -ambiciosas y costosas- no han sido replicadas prácticamente en ningún caso.

\section{Estudios sobre públicos y consumo de cine}

El consumo de cine es una de las prácticas culturales que más se ha transformado en las últimas décadas, de la mano de los cambios tecnológicos y de las reacciones empresariales que intentan conservar sus ganancias. Haciendo un breve recorrido, podemos verificar que el consumo ha cambiado drásticamente sus modalidades, pasando de las salas tradicionales de cine al consumo hogareño de cine a través de la televisión, el video y el DVD; el relanzamiento de las salas a través de los complejos multipantalla primero y del cine 3D después, para finalmente pasar al reinado del streaming legal con Netflix. Otra razón por la que resultan fundamentales los estudios de recepción cinematográfica tiene que ver con la importancia de comprender el vínculo de los espectadores con el cine nacional, puesto que ello hace a la supervivencia de la industria a través de la recaudación. A pesar de su importancia, la recepción de cine ha sido relativamente poco transitada por los estudios académicos. En los últimos años, sin embargo, el interés parece estar resurgiendo.

En cuanto a los antecedentes y estudios pioneros sobre el tema, en contraste con lo descripto para los estudios de público de museos, no hay grandes referencias internacionales que aparezcan como inspiradores para la investigación local; tampoco hay estudios tempranos hechos en la Argentina durante las décadas de 1960 y 1970, sobre los cuales construir una mirada diacrónica que permita conocer la evolución histórica del consumo de cine. El primer estudio relevante basado en encuestas que incluye datos sobre asistencia al cine, junto con otros consumos culturales, es el realizado por Landi, Vacchieri y Quevedo (1990) en la Ciudad de Buenos Aires y el Área Metropolitana. Este trabajo fue financiado por el International Development Research Center (IDRC, Canadá) y se inscribió en el Grupo de Trabajo de "Políticas Culturales" de CLACSO, en el cual ten- 
dría un gran peso la perspectiva de Néstor García Canclini sobre el consumo cultural. ${ }^{11}$ Este trabajo consistió en una encuesta de consumos y prácticas culturales, en la que se preguntaba -entre otras cosas- si se veían películas por televisión (casi el $40 \%$ afirmó hacerlo) y si les gustaba ver dichas películas (solo el 11,9\%). Según los autores "la gente sobre todo ve televisión, luego elige" (Landi, Vacchieri y Quevedo, 1990: 17). También se le preguntó a los encuestados qué programas eliminarían si pudieran definir la programación de la televisión, encontrando significativamente que lo que menos eliminarían es el cine (solo el 1,2\%). Los autores diagnostican una gran expansión comunicacional y señalan la necesidad de que la escuela emprenda la tarea de la alfabetización audiovisual.

Este tipo de investigación, que constituye un aporte muy significativo, no se reiteró en los años siguientes, conformándose entonces como una medición puntual y restringida a un espacio geográfico acotado. Ello cambió a partir de 2004 con la creación del Sistema de Información Nacional Cultural de la Argentina (SINCA) que hace encuestas periódicas sobre hábitos, consumos y prácticas culturales; el mismo Alberto Quevedo, que había participado del estudio pionero en 1990, impulsó este proyecto. La experiencia fue muy positiva y se produjeron cuatro estudios consecutivos hasta 2008. Otros estudios interesantes, también por encuestas, que incluyen datos de consumo de cine entre otros consumos culturales, fueron producidos por encargo del Ministerio de Educación de la Nación en 2005 y 2011, a través de una consultora, indagando acerca de los consumos culturales de los jóvenes en todo el país. ${ }^{12}$ Actualmente, sigue habiendo producción de estadísticas sobre consumos cinematográficos, ${ }^{13}$ pero no en el marco de trabajos de investigación más amplios y comprensivos como fue la experiencia de SINCA.

11 Se impulsaron investigaciones sobre consumo cultural en las capitales de Brasil, Chile, Colombia y México.

12 Las bases de datos de estas encuestas están disponibles para su uso. Con respecto al consumo de cine, incluyen preguntas acerca de la frecuencia y modalidad de consumo de cine en salas y en el hogar; formas en las que se selecciona la película, géneros preferidos.

13 El Instituto Nacional de Cine y Audiovisual Argentino (INCAA) produce anuarios estadísticos y el Sindicato de la Industria Cinematográfica edita DEISICA con información completa sobre el sector. 
La investigación del consumo de cine con la metodología de la encuesta fue retomada en 2010 por un equipo de investigación que se formó en la Universidad Nacional de General Sarmiento, con financiamiento de la Agencia Nacional para la Promoción de la Ciencia y la Tecnología (ANPCyT). Este equipo se ha dedicado de manera sistemática a indagar la industria cinematográfica argentina en todas sus dimensiones, incluyendo de manera central al consumo y a los espectadores. Para indagar el consumo, se hizo una encuesta a nivel nacional, a estudiantes universitarios de distintas provincias, con un total de dos mil casos. Aída Quintar y César Borello (2011) parten de un concepto de "consumo de cine" como actividad económica y cultural moldeada por el capital cultural del hogar, el entorno urbano y la disponibilidad de tecnologías. Siguiendo sus hipótesis, se analizan los patrones de consumo en función de dichas dimensiones y se encuentran correlaciones significativas. A su vez, consideran las nuevas modalidades de consumo audiovisual a partir del impacto de las nuevas tecnologías en la digitalización del cine. Los trabajos de Leandro González, del mismo equipo, agregan el concepto de "gusto" a la indagación. No se pregunta solo cuánto consumen de cine los estudiantes, sino qué les gusta del cine a los estudiantes encuestados, y por qué eligen lo que eligen, ${ }^{14}$ pues su interés se centra en la recepción del cine argentino en particular. En este conjunto de trabajos, es muy interesante la conjunción de la perspectiva de la economía política, que permite indagar las condiciones que estructuran la oferta, con la sociología de la cultura que orienta el trabajo sobre los espectadores y sus prácticas.

En cuanto a la recepción cinematográfica en distintas etapas de la historia del siglo XX, hay una serie de trabajos que, en su gran mayoría acuden a la prensa periódica y a las publicaciones especializadas del sector (revistas de cine) en tanto fuentes indirectas para acceder a la cuestión de los espectadores, lo cual es especialmente productivo -y quizá la única vía- al trabajar con períodos históricos. Un artículo de Sergio Pujol (1989) estudia la recepción del cine mudo en Buenos Aires a partir de la prensa;

14 El autor trabajó sobre las respuestas a una pregunta abierta incluida en la encuesta, en la que se pedía explicar por qué prefieren ciertas películas previamente mencionadas por ellos mismos. 
la tesis de Sergio Wolf (1996) analiza la construcción de los públicos cinematográficos en la década de 1920 a través del periodismo cinematográfico; un trabajo de Juan Samaja (2006) reconstruye la recepción del cine sonoro en la Argentina a través de las noticias de prensa entre 1929 y 1933. La investigación de María Silvia Serra (2011) se concentró en las relaciones entre cine, escuela y discursos pedagógicos a partir de las revistas educativas de comienzos de siglo. Un estudio de Joaquín Calvagno (2010) analiza las relaciones entre cine sonoro y clases trabajadoras a partir de la sección cinematográfica del semanario de la Central General de Trabajadores. El trabajo más interesante y completo desde el punto de vista teórico y metodológico es quizás el de Mariana Conde (2009), quien se ha dedicado a reconstruir los procesos sociales de la recepción cinematográfica entre 1933 y 1955, haciendo especial foco en las prácticas femeninas y en lo que califica como la "conversión de las mujeres en públicos". Esta investigación combina diferentes metodologías para comprender la recepción en un período para el cual se carece de registros sistemáticos: se recurre entonces a estimar la accesibilidad de las entradas de cine para distintos sectores sociales, contrastando salarios medios y precio del billete; se reconstruye el parque de salas de cine existente, sus ubicaciones y tipologías; se recogen testimonios orales a través de entrevistas de mujeres mayores, que fueron jóvenes en el período estudiado y se indaga también en las propias obras cinematográficas, cuáles eran los estereotipos femeninos que transmitían.

La década de 1980 fue clave para el sector cinematográfico, por el crecimiento de la televisión por cable y la introducción de la tecnología del video para ver cine en el hogar, que produjeron una crisis en el parque exhibidor y cambiaron radicalmente las maneras de consumir cine. Un solitario trabajo de Alicia Vidal (1990) se ocupa de reconstruir el ingreso de las videocaseteras a los hogares y el auge de los videoclubes en dicho período; la autora analiza la práctica de ver videos en el hogar y la opinión de los consumidores. En la misma línea, Finquelievich, Vidal y Karol (1992) indagan el proceso de difusión de la tecnología del video en los hogares, estudiando además los patrones de consumo en función de categorías sociológicas. Sobre dicho proceso, un ensayo de Schmucler y Terrero (1992) señala la introducción del video generó un proceso de privatización del consumo cultural, un retorno al espacio íntimo del hogar, para un consumo que había sido público y colectivo. Luego, un tra- 
bajo de Patricia Terrero (1999) reúne datos diversos acerca de concurrencia al cine, penetración de la videocasetera, alquileres en videoclubes, para diversas ciudades en el interior de la Argentina.

La década de 1990 estará marcada por un cierto relanzamiento de las salas de cine, a partir de su nueva localización en los shopping centers y de la aparición de los primeros complejos multipantalla, con salas más pequeñas y nuevas tecnologías que prometían mejorar la experiencia del visionado. Desde la sociología de la cultura y los Estudios Culturales, las investigaciones de Ana Wortman $(2000,2002,2008)$ se han centrado en estas transformaciones, siguiendo la evolución sociohistórica del consumo de cine en relación con las clases medias y la democratización o elitización de la cultura. Su trabajo muestra la disminución del público de cine en la Argentina desde 1970 hasta mediados de la década de 1990 y el posterior repunte del número de espectadores vinculado con la aparición de los complejos multipantalla y las salas de cine en los shoppings. Estos procesos fueron correlativos con una creciente elitización del consumo de cine, en el marco de un proceso de aumento de la desigualdad social de la mano del neoliberalismo. Según Wortman, el cine es cada vez más un consumo de clase media-alta, que se realiza en el shopping o en la intimidad del hogar (espacios socialmente homogéneos) y corresponde a un gusto único, por el predominio del consumo de películas de Hollywood. Los suplementos de espectáculos también se han utilizado para reconstruir la circulación de ciertas películas por las salas comerciales, su duración en pantalla y las estrategias de estreno, mostrando las dificultades que podría tener un espectador que quisiera ver cine no hegemónico (Moguillansky, 2011, 2008). La tesis de la elitización del consumo de cine también ha sido trabajada por Artemio Abba (2003), en una investigación que utiliza la geografía urbana para mostrar cómo ha cambiado la localización de las salas de cine, privilegiando los barrios de clase media-alta en la ciudad de Buenos Aires. Varios autores han desarrollado esta perspectiva con datos sociodemográficos acerca de los espectadores y la evolución de las salas de cine (Getino, 2009; Moguillansky, 2007). $\mathrm{Al}$ respecto, los trabajos de Emiliano Torterola (2009) muestran que, si bien el consumo de cine en salas se elitizó, también es cierto que se ha ampliado su consumo por la vía del acceso a la televisión por cable.

Los últimos años han estado signados por la digitalización de la exhibición cinematográfica en salas, por el auge de la tecnología 3D y a su vez, 
por la difusión cada vez mayor de opciones que proponen ver cine en la casa, en televisores inteligentes de gran tamaño que permiten ver películas por streaming. A ello se suma la posibilidad de ver cine en las tabletas y los celulares, expandiendo los soportes y ampliando los formatos. Al respecto, Roque González $(2011,2013)$ ha publicado diversas investigaciones que se centran en el creciente predominio de la tecnología digital y en las nuevas formas de consumo de cine por Internet. Eduardo Russo (2012) se pregunta si ahora sí triunfará el cine tridimensional, lo coloca en perspectiva histórica y muestra la novedad de la situación actual, en la que la tecnología 3D se integra a la concepción del film y de su circulación y/o explotación en diversas plataformas y mercados auxiliares; también señala que los usuarios de YouTube pueden producir sus propios videos tridimensionales. Algunos autores reflexionan sobre estos cambios, preguntándose si estamos viviendo el fin del cine (por el declive de la tecnología analógica) o su expansión y mutación radical (Laferla, 2013). Las transformaciones de la recepción y de la crítica con la aparición de las redes sociales ${ }^{15}$ han sido señaladas por Wortman (2009).

Existen investigaciones específicas sobre ciertos géneros y sus públicos. Así, la investigación de María Cecilia Díaz (2011) sobre los fans del anime en Córdoba es un buen ejemplo de las muchas investigaciones que existen sobre los micro-universos pre-juveniles. Díaz describe minuciosamente las prácticas de los aficionados, que son mucho más amplias que el mero disfrute de una proyección, y que involucran clubes de juego, competencias, coleccionismo y fiestas a las que se concurre caracterizado como alguno de los personajes de preferencia (cosplay). También la apropiación es un elemento central de estas prácticas: los aficionados crean o recrean sus propias historietas o cortos animados y los ponen en circulación en la web. Díaz utiliza una aproximación etnográfica a distintos grupos de aficionados en Córdoba, que le permite entender los vínculos que los miembros de una determinada comunidad establecen.

15 "El tradicional boca a boca, de nuestros grupos de amigos más próximos se actualiza, se amplifica en las redes sociales y quizá con estas redes pesa más lo que se dice en ellas acerca de una película o un conjunto musical que lo que diga la prensa gráfica a través de su sección de Espectáculos. Aparece como una nueva forma de la crítica que tamizaba un hecho cultural" (Wortman, 2009: 107). 
El cine de animación también es ocasión para que Mónica Kirchheimer reflexione sobre la emergencia de un nuevo tipo de público: el kidult o adultescente. El cambio detectado tiene su centro en una modificación de la destinación de las películas animadas; ya no son solo infantiles. Los rasgos diferenciales de este conjunto de películas implican la infantilización de lo adulto (especialmente por el espacio dedicado a actividades lúdicas, la colección de memorabilia, los homenajes) y la adultización de los niños (asociado al mundo de la indumentaria y las actitudes). La investigación presenta un espacio de circulación discursiva que se vio modificado en los últimos veinte años, y que pone en juego nuevos criterios clasificatorios.

Finalizando esta revisión, interesa señalar la importancia de algunos trabajos que no han sido el centro de nuestro interés porque no estudian directamente el consumo de cine, pero aportan a su comprensión. Nos referimos a trabajos que, desde la economía política del cine y/o de las industrias culturales, han estudiado cómo inciden la concentración de la industria cinematográfica (en particular en la distribución y la exhibición), la lógica mercantil de explotación de las películas y las políticas públicas que regulan al sector inciden con fuerza y eficacia diversas en la conformación de la oferta cinematográfica. Nos referimos centralmente a los trabajos de Getino (2006, 2008), Marino (2013), Moguillansky (2011), Perelman y Seivach (2005) y Borrello y Quintar (2012).

Teatro

Los estudios sobre teatro encuentran representación regional en Córdoba y en Formosa. En el primer caso, los resultados de una investigación liderada por Graciela Frega se publicaron en 2004 con el título El teatro en Córdoba (1900-1930): documentación y crítica. En esta obra,el capítulo escrito por Ana Yukelson, "Conformación, motivación y gusto del público cordobés", está dedicado al tema del público. Siguiendo este antecedente, Paula Beaulieu actualiza la información histórica al caracterizar el consumo actual de teatro local (que en Córdoba corresponde preponderantemente al teatro independiente), a partir de una investigación que incluye tanto entrevistas con realizadores y referentes del teatro cordobés, como 
una encuesta a los espectadores. La investigación en campo insume un año de trabajo, lo que le permite recorrer las variaciones estacionales, es decir que abarca tanto las temporadas de mayor como las de menor afluencia de público. La información relevada sobre el público toma en cuenta factores de caracterización del espectador (edad, sexo, nivel de educación y formación cultural), factores de caracterización del proceso de decisión de adquisición de una entrada (búsqueda y recepción de información, factores determinantes de la elección y criterios de selección de las obras), factores de caracterización del proceso de consumo (frecuencia y repetición de asistencia, valoración de las exhibiciones, nivel de satisfacción y percepción del teatro independiente). El objetivo de esta investigación es considerar todo el circuito relativo al teatro: creación, su producción, distribución y comercialización; describir el contexto de la oferta en la que se produce la elección de una obra y la asistencia al teatro y caracterizar al público del teatro en Córdoba. Con una base teórica derivada de los estudios de televisión, este trabajo intenta superar las limitaciones de las metodologías que se centran sobre el consumo para ofrecer una lectura más amplia que sirva a la toma de decisiones en políticas culturales. Los resultados de la investigación señalan que el teatro independiente en Córdoba prácticamente no incorpora público nuevo, solo un $3 \%$ que no compensa el decrecimiento constante. Por un lado, "hay una correlación entre este dato y la falta de planificación y de asignación presupuestaria de las producciones teatrales para la difusión y comunicación de las funciones, la utilización de formas de comunicación prácticamente no mediadas como la pegatina de afiches y el boca en boca, y la poca visibilidad en los medios de comunicación que se reduce a la publicación de gacetillas, la aparición en la grilla de espectáculos y la mención en algunos programas de radio FM" (Beaulieu, 2008: 131). Por otro, los creadores manifiestan que no están dispuestos a hacer concesiones con el espectador real y esperan de él que pueda realizar valoraciones apreciativas como si fuera el espectador modelo.

El segundo núcleo importante sobre estudios de recepción en teatro es el que se organiza en torno a Andrea Fernández, en Formosa. Fernández (2013) estudia los rasgos del público formoseño de teatro. La autora hizo entrevistas a espectadores, a partir de las cuales indica que el público acude al teatro motivado por el interés en presenciar un espectáculo artístico y 
para apoyar las producciones de teatro independiente formoseño. Se afirma que la divulgación es centralmente de boca en boca y que el teatro es una actividad amateur autofinanciada por los teatristas.

En cuanto a estudios cuantitativos de públicos, encontramos segmentos relativos al teatro en sondeos más generales. El "Estudio Nacional de Público Teatral” (Cerdeira y Sánchez Salinas, 2008) se aboca específicamente a este arte escénico. Se realizó entre 2011 y 2012, bajo dirección del Instituto Nacional del Teatro y consistió en encuestas de opinión con un enfoque cuantitativo, con muestras estratificadas por sexo y rango de edad. El relevamiento se ejecutó durante las Fiestas Nacionales de Teatro, en el Circuito de Festivales y en Fiestas Provinciales de Chaco, Chubut, Corrientes, Entre Ríos, La Pampa, La Rioja, Mendoza, Misiones, Salta, San Juan y Tucumán. Entre los hallazgos del estudio, se indica que el público de teatro es mayoritariamente joven, femenino, universitario y de clase media; se encontró que la frecuencia de asistencia al teatro varía siendo mayor en Chaco, La Pampa y Mendoza, y menor en La Rioja, San Juan, Salta y Misiones. ${ }^{16}$

\section{Danza y festivales}

Como mencionábamos antes, la recepción de la danza es apenas considerada. Se ofrece como objeto de interés en el marco de festivales o rituales especiales. Entre los trabajos escasos trabajos al respecto, subrayamos los producidos por Juan Armando Guzmán. En ellos, encontramos tanto un interés por los aspectos identitarios y religiosos del público, como una consideración relativa a la danza misma en sus aspectos estéticos. Interesado en el arte de su región, Jujuy, Guzmán realiza etnografías de fiestas callejeras, corsos y procesiones. En el baile de Caporales y Tinkus que se producen en las procesiones religiosas observa un símbolo de fe pero también descubre que se produce un momento de la "apertura" de la procesión: es el momento donde la danza - desplegada en la calle- parece cobrar

16 Se hicieron informes detallados por provincia que están a disposición en la página web del Instituto Nacional del Teatro, en http://www.inteatro.gov.ar/2008/estadisticas. php. 
autonomía del vínculo referencial (Guzmán, 2010a). De esta manera el baile es abordado como una práctica artística que produce un efecto particular en relación al símbolo religioso: la danza de estos cuerpos de baile parece no estar sometida a fuertes condicionantes de la ceremonia, sino a las condiciones de regulación de sus propios miembros, que se expresa en la modalidad estética de los pasos de baile, donde el guión y la improvisación dan sentido a la danza. Para el autor, las danzas de origen boliviano expresan, de alguna manera, la opinión de los sectores populares sobre la exclusión, convirtiéndose en "materiales de protesta".

$\mathrm{Al}$ analizar el Corso de la ciudad de San Salvador de Jujuy como actividad cultural programada oficialmente en el marco de los festejos por carnaval, nuevamente retoma los vectores de análisis presentes en la investigación anterior, en tanto reivindicación de la calle como lugar de interacción, enfatizando en este caso el constante intercambio de papeles entre actores y público.

En la región de Cuyo, encontramos el trabajo de Gimeno (2012) sobre la Fiesta Nacional del Sol que se realiza en la provincia de San Juan y que se ha constituido en los últimos años en la máxima celebración de esa provincia. El autor historiza la participación del público en esta fiesta que data de 1972 y estudia la inclusión de algunos elementos de festividades populares previas - carnavales, murgas y corsos- que aparecen configuradas como espectáculo turístico en la versión actual de la fiesta, interrogando la distinción entre pueblo y público. La Fiesta Nacional del Sol, constituida en máxima celebración de la provincia de San Juan, es ocasión de análisis de los procesos de industrialización y espectacularización que operan en su producción que implican la necesaria aceptación de los códigos impuestos desde el sector dominante.

Música y baile

Las investigaciones sobre públicos de distintos estilos y géneros musicales es sin dudas la más desarrollada. Se destaca el abordaje de ciertos estilos, privilegiadamente el rock (rock chabón, rock nacional) y en menor medida, la música electrónica, la cumbia villera, el cuarteto, el tango y la música electroacústica. 
Las investigaciones sobre públicos musicales están fundamentalmente ligadas a:

La música como performance configuradora de subjetividades. En este grupo de investigaciones hay una lectura focalizada en sus puestas en escena y en el cuerpo como lugar de la experiencia. Suele incluirse en esta perspectiva la consideración del "baile".

Mientras que algunas vertientes musicológicas y semióticas se concentran en las líricas y la significación -privilegiándose una perspectiva discursiva que queda fuera de los límites de este análisis-, en el abordaje de los públicos emerge de manera crucial la necesidad de interpretar los cuerpos -en especial, los cuerpos generizados-. En esta vertiente, la música aparece inescindiblemente ligada a la danza, el evento del baile o en un sentido más general, la performance, entendida como actuación, pero también asumida como un enfoque fructífero para este tipo de análisis. En este sentido, la investigación de María de los Ángeles Montes sobre prácticas de baile y escucha de música en las milongas cordobesas, muestra el baile como una trama donde el espacio -y sus convenciones-, la música y la danza se entretejen. Ejemplos de esta modalidad de abordaje son las investigaciones de Gustavo Blázquez (2008a, 2008b, 2011, 2012a, 2012b), Silvia Citro (2000, 2005, 2006, 2008, Citro y Cerletti 2008; Citro y Ascheri, 2012) y Víctor Lenarduzzi (2012). En general, los marcos conceptuales provienen de los estudios de género (Butler especialmente), el postestructuralismo y la antropología interpretativa

Los trabajos de Gustavo Blázquez abordan predominantemente dos géneros musicales: el cuarteto cordobés y la música electrónica. En una década de producción sobre estos temas, explora distintas aristas vinculadas al género, el baile, la forma de establecer relaciones, la raza, la clase social, la escena dance y el baile de cuarteto, el erotismo, el cuerpo. Desde una perspectiva básicamente etnográfica, la música ingresa en su análisis como una performance completa. Blázquez centra su atención en los públicos y sus prácticas en el momento del baile. Otro de los aspectos significativos de su trabajo es su capacidad de abordar el "detrás de la escena”. A través de entrevistas con intérpretes y productores, se introduce en las condiciones materiales de la producción y circulación musical, entendida también como mercancía, así como en la puesta en escena, la performance de los músicos, la significación identitaria de esa práctica, la configuración 
de cuerpos y subjetividades, las relaciones entre los miembros de los públicos y sus intereses en relación a estas prácticas culturales. Género, raza y clase resultan ejes transversales de sus investigaciones que permiten articulaciones horizontales con prácticas sociales abordadas por otros subcampos de la sociología y la antropología.

Sobre la escena de la música electrónica y alcanzando conclusiones convergentes con las de Blázquez, el libro de Víctor Lenarduzzi revisa, desde el campo de la filosofía y el arte, el lugar de práctica "contemplativa" asignada a la recepción musical y cuestiona las clásicas dicotomías alma/ cuerpo, racionalidad/sensibilidad que envolvieron su estudio. En cambio propone recuperar el lugar del cuerpo en la reflexión, en especial para esta investigación sobre música electrónica, que propicia la experiencia sensorial. El capítulo IV del libro se ocupa de la recepción musical en las fiestas raves, y señala, al igual que Blázquez, el desplazamiento de la seducción como objetivo.

Guadalupe Gallo (2011), utilizando como llave metodológica y conceptual la noción de performance y retomando consideraciones de Blázquez y Lenarduzzi, también revisa la escena dance, señalando que aquí, la música y el baile están completamente implicados y que existe un diálogo constante entre el DJ y lo que se manifiesta en la pista.

En ese sentido, las investigaciones de Silvia Citro son un fuerte ejemplo de la potencialidad que ofrece la conjunción música-danza para el abordaje del cuerpo. Interesada inicialmente por las prácticas musicales de distintos grupos étnicos argentinos (especialmente tobas y mocovíes), sus investigaciones se ofrecen como un desarrollo conceptual fundamental para el abordaje del cuerpo en su relación con las performances musicalesdancísticas analizadas en su dimensión ritual y en su relación con las identidades culturales. A partir de este instrumental teórico y metodológico, Citro también aborda el rock y los jóvenes, explorando los recitales como espacios festivo-rituales de pasaje y transgresión. La investigación de Marisa Vigliotta retoma los conceptos de ritual y fiesta de Citro y los aplica, como ella, al abordaje del rock $(2011,2013)$.

La música como articuladora de identidades sociales, vinculada a la agenda de investigación sobre las culturas populares.

Esta entrada al problema es la más antigua y la más transitada, al punto que la producción existente admite una segunda especificación. Si- 
guiendo a Aliano (2010), podemos decir que se distinguen dos posiciones que, sin ser antagónicas, presentan matices distintos en el interior del campo: los que entienden a las culturas populares desde el lugar de la subalternidad -que posibilita asimismo resistencias-, y los que enfocan su positividad, soslayando la dimensión política. El primer tipo de estudios se ejemplifica en los trabajos de Pablo Alabarces - precursor de estos estudios en la Argentina (1993), junto con Mirta Varela (Alabarces y Varela, 1988) - y María Graciela Rodríguez (Alabarces y Rodríguez, 2008), Daniel Salerno (2008) y Malvina Silba (Salerno y Silba, 2006). Estas investigaciones retoman conceptos clásicos como identidad o culturas populares, desde una perspectiva inspirada en los Estudios Culturales ingleses e influida por Gramsci, El segundo grupo, estimulado en las investigaciones de Pablo Vila y Pablo Semán (1985; 1996; Semán y Vila, 2008) y Pablo Semán (2006a) escoge una perspectiva socioantropológica interpretativista (Garriga Zucal, 2008; Martín, 2008; Semán y Vila, 2008; Welschinger Lascano y otros, 2011).

En este amplio grupo de investigaciones, existen algunos cruces específicos. Un cruce temático especial es el estudio de los vínculos y definiciones identitarias juveniles conformados alrededor de ciertos estilos musicales, grupos o intérpretes (Wortman, 2001; Benedetti, 2008; Aliano y otros, 2011). Esta relación constituye una "novel tradición” o subcampo; numerosos trabajos de los precedentemente referidos incluyen alusiones a esta relación. La emergencia de los estudios de juventudes y los estudios de rock en la Argentina es contemporánea; las trayectorias y las agendas investigativas rápidamente coinciden (Bustos Castro, 1994; Kuasñosky y Szulik 1994; Pujol, 2007) y siguen hoy en diálogo fructífero.

Un segundo cruce temático especial es el que establece relaciones entre grupos sociales y consumos musicales (Míguez, 2006), fragmentando la perspectiva culturalista de las culturas populares. Aunque hay cierta diversidad, aquí la entrada resulta mucho más cercana a la de "públicos". Menos habituales son las lecturas que, a la inversa, previenen contra la naturalización automática de la relación entre ciertos géneros y estilos musicales y determinados grupos sociales o etarios, por ejemplo rock y juventud (Welschinger Lascano y otros, 2011), o cumbia villera y marginalidad (Silba, 2010).

Un tercer cruce temático especial es la relación entre públicos y religiosidad popular. Esta entrada, que resulta sugerente, sobre todo en las 
relaciones conceptuales establecidas entre "fans" y "devotos" (Martín, 2009), puede terminar resultando un poco forzada en la medida en que se aplique indiferenciadamente (Semán, 2006b; Gallo y Semán, 2009), sin destacar la peculiaridad que las prácticas (ya sean religiosas o culturales) revisten.

En el balance de las investigaciones sobre música y danza se hace evidente la dificultad de atender a todas las dimensiones de la problemática. La atención privilegiada de la recepción (entendida siempre en términos colectivos, como público, fans, seguidores, aficionados, e incluso "devotos") eclipsa -salvo excepciones- el análisis de las condiciones de producción y, sobre todo, del objeto artístico mismo en lo que a sus dimensiones estéticas y técnicas se refiere. Estos aspectos hablan del qué y del cómo de la recepción. Son dimensiones significativas, inherentes a la interpretación de las condiciones de recepción, que superan la consideración reducida al receptor empírico y podrían, fructíferamente, ser integradas en la investigación, en lugar de desgajarse por separado. Algunos intentos por reunir los fragmentos y ampliar los alcances de una investigación sobre la recepción van por la vía de las entrevistas a los grupos e intérpretes, o el análisis de entrevistas o documentos publicados en la prensa. Algunas investigaciones, como hemos visto, se preocupan especialmente de la historización o la tradición del género musical seleccionado (Lenarduzzi, Blázquez, Alabarces, Citro).

Esta segmentación entre la producción cultural y sus públicos también se presenta a la inversa: existen abordajes que se refieren a sus dimensiones significantes ligadas fundamentalmente a las líricas y géneros (Díaz, 2000, 2009) que no atiende especialmente la caracterización de los receptores empíricos - por esa razón, no han sido reseñados en este volumen-. Existe aquí un problema de formación: la mayor parte de los investigadores provienen de las ciencias sociales (sociólogos, antropólogos, comunicólogos) y su sensibilidad en cuanto a su objeto de estudio los lleva a privilegiar la mirada sobre el sujeto en su trama sociocultural. Aunque algunos de ellos son además aficionados que han adquirido algunas herramientas de crítica musical, en general no hay un despliegue importante de estos análisis. Si el interés está puesto en el acto de encuentro entre músicos y público, el motivo de este ritual, e incluso, el don intercambiado, son centrales para comprender la práctica: los "sentidos" se atan a un objeto significante y la performance cor- 
poral acompasa una música que sin embargo queda eclipsada en las investigaciones.

\section{Casos marginales}

Un caso marginal, cuya pregunta y abordaje resulta original, es el de Fabián Beltramino $(2003,2010)$. La pregunta no es por los públicos, sino por su ausencia, en la música electroacústica: "se trata -dice Beltraminode un producto que parece no necesitar de consumidores, un producto que agota sus expectativas de consumo en los propios productores" (2003: 12) A partir de un conjunto de entrevistas a informantes clave (compositores, productores) y algunas encuestas en los escasos conciertos localizados en Buenos Aires identificados, Beltramino elabora una serie de hipótesis sobre este distanciamiento que toma nota de una manera especial el lenguaje musical electroacústico y la ausencia de un intérprete. Caracteriza también el tipo de público (experto o de culto, casi siempre "casi siempre vinculado de manera directa a la producción, sea en el campo mismo de la música académica” (2003: 18), los sus canales de difusión y la excepcionalidad de los conciertos. Indaga, además, sobre la experiencia de audición en relación con las características de la música. La investigación incluye claves teóricas provenientes del campo artístico (Adorno, Eco) que permiten interrogar a los públicos desde aspectos intrínsecos a la obra musical.

Otro caso marginal es el libro de Claudio Benzecry (2012). El fanático de la ópera es un acercamiento claramente empírico al arte dramático, que busca analizar de forma integral el circuito en el que se encuentra inserto el espectador. El trabajo se detiene a pensar las relaciones entre los fanáticos de la ópera y su vínculo afectivo con ese objeto cultural. Busca superar las limitaciones deterministas de la sociología bourdeana, dejando de lado la noción de distinción como elemento fundamental en la elección de ciertas prácticas artísticas y culturales. Intenta pensar el vínculo entre los sujetos y la ópera desde una perspectiva que pone de relieve lo pasional, en términos de amor a la ópera. "Este libro se centra en el carácter afectivo del apego a la ópera -un producto cultural particularmente complejo- y en su utilización como una actividad significativa que permite a sus apasionados amantes inventar un sentido dentro de su propia vida, incluso 
darle un sentido a esta y modelarse como individuos meritorios" (Benzecry, 2012: 25).

El autor propone como punto de partida un recorrido por la historia de la ópera en la Argentina que le permite explicar las relaciones entre una práctica cultural habitualmente asociada a la alta cultura y su pervivencia en el tiempo y actual vinculación con sujetos pertenecientes a las clases medias, preguntándose "¿Qué explica esa entrega intensiva y extensiva cuando el estatus, la ideología y la popularidad no son suficientes?” (Benzecry, 2012: 25). La metodología seleccionada fue una etnografía realizada durante 18 meses, durante las temporadas 2002 a 2005. La etnografía se concentró en los recintos del piso superior del Teatro Colón de Buenos Aires, destinados al público que observa de pie las funciones, asistiendo a unas setenta representaciones y compartiendo las esperas previas al ingreso o los viajes a teatros no muy distantes de Buenos Aires. Cumplió seis meses de observación previos a la realización de cuarenta y cuatro entrevistas, entre los miembros del público, críticos musicales, productores y organizadores clave, en las que preguntaba a los entrevistados sobre su iniciación en las actividades musicales, su historia familiar, su trayectoria personal, su conocimiento musical y frecuencia con la que asistían a la ópera. El objetivo de estas entrevistas fue comprender y hacer explícitos algunos de los lazos entre la vida personal, el estatus social, las concepciones de trascendencia y goce y el apogeo de la música a los que era difícil dar forma solo mediante la observación (Benzecry, 2012: 38).

\section{Conclusiones}

Convergencias temáticas, teóricas y metodológicas

En la mayor parte de las investigaciones relevadas, encontramos una presencia marcada de los conceptos de la sociología de la cultura bourdeana, en particular el concepto de habitus y la noción de capital cultural. Los trabajos oscilan entre un enfoque descriptivo, o puramente teórico-especulativos, con escasa o no suficientemente explotada evidencia empírica. En casi todos los casos se omite dar cuenta del diseño metodológico. 
En cuanto a los campos artísticos relevados, podemos decir que los estudios sobre públicos corren suertes dispares. El público de la danza, por ejemplo, es poco abordado. Cuando lo es, se pone integra al estudio de las identidades culturales y étnicas. La mayor vacancia relativa se observa en relación con el público de teatro. A la inversa, el público de la música ha recibido una especial atención. En tanto ha sido punta de lanza de los debates teóricos que redundan en concepción de cultura e identidad, e incluso en la conformación de públicos o subculturas, registra una frondosa producción académica.

Las tradiciones de investigación se hacen eco de estas tensiones, privilegiando ciertos objetos y desatendiendo otros. Los abordajes varían sustancialmente en función de las sedes disciplinares que se interesan por ellos. Así, las danzas y la música populares son asunto de la antropología, proliferando los estudios locales o situados; mientras que el ballet, el teatro y el cine son objetos de las Letras o las Escuelas de Arte. Aunque estos abordajes suelen interesarse más por la práctica artística que por los públicos, eventualmente se refieren a ellos. Las lógicas de investigación se dividen con claridad entre los dos enfoques dominantes: el sociológico de lógica cuantitativa y el antropológico o cualitativo situado y microscópico representado fundamentalmente por los estudios de caso. Marginalmente, encontramos algunas investigaciones multidimensionales y pluridisciplinares, que consideran tanto el objeto artístico como sus públicos.

Esquematizando un poco, podríamos decir que existen dos maneras hegemónicas de concebir las prácticas culturales, que se manifiestan a su vez al estudiar los públicos: una, en tensión con el mercado cultural del arte y de las industrias culturales; la otra, en relación con territorios, identidades y tradiciones.

\section{Perspectivas innovadoras y agendas pendientes}

Las tendencias que emergen en los últimos años de la década analizada prestan atención a la mixtura del arte con las tecnologías digitales. Como ocurre en los demás subcampos de las prácticas culturales, estas tecnologías obligan a redefiniciones en términos de acceso, difusión, posibilidades de intervención en la producción y edición y recreación de la pieza. Por el 
momento, solo se relevan algunas lecturas y problematizaciones preliminares o aisladas (Ugarte, 2008; Nieto Zuljevich Karaman, 2011).

A la luz del panorama descrito, emergen algunos interrogantes. Es llamativa la vacancia en el estudio de los públicos de algunas artes, habida cuenta la muy escasa cantidad de investigaciones encontradas: es el caso de la danza, el teatro y ciertas formas musicales como la electroacústica. Quizá, como Beltramino, podemos preguntarnos si se están convirtiendo en universos autorreferentes, y variar la pregunta para interesarnos por la "vida social" de ciertos estilos artísticos.

La agenda pendiente en los estudios del público de artes probablemente suponga un esfuerzo de articulación de perspectivas. Sin dudas, la investigación ganaría densidad si se lograran captar de manera global e integrada todas las etapas de las prácticas artísticas (creación y la producción, difusión, legitimación en la crítica, exposición y puesta en escena, recepción), así como una lectura que vaya del contexto a la obra, de la obra al público, del público al contexto.

La ausencia más significativa es la consideración de la experiencia estética como una dimensión de análisis inseparable de la recepción de las prácticas artísticas. Sin dudas esto requiere refinar las herramientas metodológicas a partir de un concepto que, en sí mismo, presenta una enorme complejidad y es objeto de debate. No obstante, esta es la peculiaridad de este tipo de recepción. Al abandonar aquello que le es propio, la experiencia estética se iguala al consumo de cualquier mercancía.

En relación con estas prácticas y su recepción, restan contestar tres observaciones: ¿hay un valor diferente en la fruición, si esta es educada?, ¿cuál es la relación entre la delectación y la obra? y ¿qué valor artístico tienen las obras y los géneros descalificados? La omisión de la consideración de la obra misma cuando se investigan los fenómenos de recepción, y por tanto, la carencia de un análisis en torno a la relación estética de los públicos con las obras artísticas en su dimensión significante, oblitera una dimensión única, inherente a estas prácticas, igualándolas a cualquier otra. Si son válidas las mismas categorías para analizar el fútbol, la religión, el consumo de bienes generales y las prácticas artísticas, es porque se produce una homologación que soslaya lo que es particular, específico, en la recepción del arte, esto es: la experiencia estética. Esta dimensión, subjetiva y social al mismo tiempo, no se incluye, salvo ex- 
cepciones, en los análisis del corpus de estudios de públicos que hemos relevado.

\section{Referencias bibliográficas}

Bayardo, R. y Wortman, A. (2012), "Consumos culturales en Argentina”, Alteridades, $\mathrm{N}^{\circ} 44$ (22), pp. 11-21.

Bourdieu, P. (1979), La Distinction, Critique sociale du Jugement, Éditions de Minuit, París.

— (1992), Les règles de l'art, Seuil, París.

Bourdieu, P. y Darbel, A. (1966), L'Amour de l'Art. Les Musées d'Art Européen et leur Public, Éditions de Minuit, París.

Carozzi, M.J. (coord.) (2011), Las palabras y los pasos. Etnografias de la danza en la ciudad, Gorla, Buenos Aires.

Eagleton, T. (1998), Una introducción a la teoría literaria, Fondo de Cultura Económica, México.

Francastel, P. (1960 [1951]), Pintura y sociedad, Emecé, Buenos Aires.

Frith, S. (1978), The Sociology of Rock, Constable, Londres.

Gadamer, H.-G. (1977 [1960]), Verdad y método I, Sígueme, Salamanca.

García Canclini, N. (coord.) (1987), El público como respuesta. Cuatro estudios sociológicos en museos de arte, INBA, México.

Getino, O. (1994), Las industrias culturales en la Argentina, Colihue, Buenos Aires. Gombrich, E. (1997), La historia social del arte, Debates, Madrid.

Hall, S. (1980), "Encoding and Decoding in the Television Discourse", en Hall, S., Hobson, D., Love, A. y Willis. P. (eds.), Culture, Media, Language, Hutchinson, Londres, pp. 128-138.

Hauser, A. (1969 [1951]), Historia social de la literatura y el arte, Guadarrama/ Punto Omega, Madrid.

- (1975), Sociología del arte, Guadarrama, Madrid.

- (1982 [1958]), Teorías del arte. Tendencias y métodos de la crítica moderna, Punto Omega, Madrid.

Martín Barbero, J. (1997 [1987]), De los medios a las mediaciones. Comunicación, cultura y hegemonía, Gustavo Gilli, Barcelona.

Sснмilchuк, G. (1996), "Venturas y desventuras de los estudios de público", Cuicuilco, nueva época, $\mathrm{N}^{\circ} 7$ (3), pp. 31-57. 
Sunkel, G. (2006), El consumo cultural en América Latina. Construcción teórica y lineas de investigación, Convenio Andrés Bello, Bogotá (2a edición ampliada y revisada).

\section{Corpus analizado}

Museos, artes plásticas y visuales

Baldasarre, M. I. (2006), Los dueños del arte, Edhasa, Buenos Aires.

Baldasarre, M.I. y Dolinko, S. (2011), Travesías de la imagen. Historias de las artes visuales en Argentina, CAIA/EDUNTREF, Buenos Aires.

BAYARDO, R. (2001), "Cultura, artes y gestión cultural. La profesionalización de la gestión cultural", en III Jornadas de Investigación del Instituto de Historia del Arte Argentino y Latinoamericano, FFyL, Universidad de Buenos Aires, Buenos Aires.

- (2004), La economía cultural, las políticas culturales y el financiamiento público de la cultura, Turismo y Patrimonio 4, pp. 57-68. Lima, Universidad de San Martín de Porres.

— (2007), "La gestión del patrimonio y los conflictos en torno a las identidades sociales. ¿Gestión cultural sin políticas culturales transversales?”, Papeles de Trabajo, No 2. Recuperado de http://www.idaes.edu.ar/papelesdetrabajo/paginas/Documentos/02_4_bayardo\%20gestion\%20patrimonio\%20y\%20politicas\%20culturales.pdf.

Bermejo, T. (2014), El precio de la belleza. Coleccionismo y consumo artístico en Argentina (1920-1960), EDUNTREF, Buenos Aires.

Bialagorski, M. y Cousillas, A. M. (2000), "Gestión cultural y estudios de público en el Museo Hernández de la ciudad de Buenos Aires”, Cuadernos de Antropología Social, N¹2, pp. 195-205.

- (2008), "Una propuesta de evaluación innovadora en los estudios de visitantes de un museo de Buenos Aires", Mus-A, Revista de los Museos de Andalucía, N ${ }^{\circ}$ 10, pp. 98-101.

Bialogorski, M. y Fritz, P. (2011), “Cómo impacta la noche de los museos en los visitantes? Un estudio de público en la ciudad de Buenos Aires”, Investigación inédita, Buenos Aires, International Council of Museums (ICOM)Argentina. 
Bialogorski, M. y Lander, E. (1999), "Viejas ideas, nuevos públicos: acerca de un estudio de público en el Museo Hernández", en Comunicación en Museos y diversidad cultural - Viejas culturas, nuevos mundos. VII Seminario Latinoamericano sobre Patrimonio Cultural, ICOM-CA, Buenos Aires.

Cerviño, M. (2007), "No, yo tampoco. El amor al arte, probablemente" Apuntes de Investigación del CECyP, № 12, pp. 183-198.

- (2011), El circuito internacional del arte contemporáneo en los primeros noventa. Una descripción del llamado "arte global", Documentos de jóvenes Investigadores, Instituto Gino Germani. Recuperado de http://webiigg.sociales.uba. ar/iigg/textos/documentos/DJI32.pdf.

Conforti, M.E. (2012), "El público y el patrimonio arqueológico. El caso de la comunidad de Tres Arroyos en relación con el sitio 'Arroyo Seco 2' y la muestra del Museo Municipal José A. Mulazzi”, Revista del Museo de Antropología, $\mathrm{N}^{\circ}$ 5, pp. 131-140.

Cousillas, A.M. (1997), "Los Estudios de Visitantes a Museos: Fundamentos generales y principales tendencias", $N A y A$. Recuperado de http://www.equiponaya.com.ar/articulos/museologia02.htm.

- (2001), "Sobre patrimonio cultural, imaginarios y conflictos", en Temas de Patrimonio, 5, Primeras Jornadas de Patrimonio Intangible "Memorias, identidades e imaginarios sociales", Buenos Aires, Comisión para la Preservación del Patrimonio Histórico Cultural de la Ciudad de Buenos Aires, pp. 212-218.

- (2003), "Reflexiones desde la gestión sobre el patrimonio cultural artesanal en un museo de la ciudad de Buenos Aires", Ponencia, Primer Congreso Universitario de Folklore, Universidad Nacional de Córdoba, 20 al 23 de junio de 2003.

Cousillas, A.M. y otros (1998), "Frecuentación y consumo cultural del público a museos. Aportes para repensar la política cultural en Buenos Aires”, en I Congreso Virtual de Antropología y Arqueología. Recuperado de http://www. equiponaya.com.ar/congreso/ponencia3-2.htm.

Fritz, P. y Bialogorski, M. (2012), “Diálogo con los visitantes. Estudios de público cualitativos en el Museo de Arte Popular José Hernández de la Ciudad de Buenos Aires", Ponencia, Simposio internacional de museología. Nuevas prácticas, nuevas audiencias. A 40 años de la mesa de Santiago, Santiago de Chile.

Gibaja, R. (1964), El público de arte: encuesta en el Museo Nacional de Bellas Artes, Eudeba, Buenos Aires. 
Plante, I. (2013), Argentinos de París. Arte y viajes culturales durante los años sesenta, Edhasa, Buenos Aires.

Puebla Antequera, F. (2012), "Enfoques temáticos-conceptuales desarrollados en estudios de público", Revista de Museología, № 55, pp. 50-55.

Schmilchuк, G. (2012), Públicos de museos, agentes de consumo y sujetos de experiencia, Alteridades 22 (44): 23-40.

Verón, E. y Levasseur, M. (1983), L'espace, le corps, le sens: ethnographie d'une exposition: "Vacances en France", BPI/Centre Georges Pompidou, París.

Cine

Aвва, A. (2003), "Cine y ciudad en el siglo XX. Evolución de las centralidades culturales de Buenos Aires", Documento de Trabajo CIHaM, N 4, FADU-Universidad de Buenos Aires. Recuperado de http://www.ciham.org/CIHaM\%20 FADU-UBA_files/bib-abba2003.pdf.

Assusa, G. (2013), "Distinción, consumo y clases sociales. Elementos para una sociología de la práctica de consumo cinematográfico”, Estudios sobre las Culturas Contemporáneas, $\mathrm{N}^{\circ} 38$, pp. 93-120.

Calvagno, J. (2010), “El primer cine industrial y las masas en la Argentina: la sección 'Cinematografía' del semanario 'CGT'”, A Contracorriente. Una revista de historia social y literatura de América Latina, $\mathrm{N}^{\circ} 7(3)$, pp. 38-81.

Conde, M. (2009), Martes, dia de damas. Mujeres y cine en la Argentina, 19331955, Tesis de Maestría, FCS-Universidad de Buenos Aires. Recuperado de http://lanic.utexas.edu/project/laoap/iigg/tesis7.pdf.

DíAz, M.C. (2011), "Anime en proyección: Ciclos de animación japonesa en la ciudad de Córdoba”, en VII Encuentro Interdisciplinario de Ciencias Sociales y Humanas, Diálogo entre saberes: encuentros y desencuentros, Córdoba.

Finquelievich, S., Vidal, A. y Karol, J. (1992), Nuevas tecnologias en la ciudad: información y comunicación en la cotidianeidad, Centro Editor de América Latina, Buenos Aires.

Getino, O. (2005), Cine argentino. Entre lo posible y lo deseable, CICCUS, Buenos Aires.

- (2006), El capital de la cultura. Las industrias culturales en Argentina y en la integración MERCOSUR, Parlamento Cultural MERCOSUR, Buenos Aires.

- (2007), Cine iberoamericano. Los desafios del nuevo sigo, CICCUS, Buenos Aires. 
- (2008), "Apuntes sobre la incidencia económica y social del cine y el audiovisual", en Getino, O. y otros (coords.), Cuadernos de Políticas Culturales. Indicadores Culturales 2008, EDUNTREF, Buenos Aires, pp. 114-123.

- (2009), Industrias del audiovisual argentino en el mercado internacional. El cine, la televisión, el disco y la radio, CICCUS, Buenos Aires.

González, L. (2011), "Cine argentino. Gusto, recepción y consumo. Primeras aproximaciones", en XXVIII Congreso Internacional ALAS, Recife. Recuperado de http://www.ungs.edu.ar/ms_ico/wp-content/uploads/2012/03/LGPonencia-ALAIC-2012-Uruguay.pdf.

- (2013), "De la sala a la 'nube'. Nuevas perspectivas en el consumo de filmes y audiovisuales en el mundo digital", en Piñón, J.F. (coord.), Cuadernos de politicas culturales. Indicadores culturales 2012, s/n, UNTREF, Buenos Aires.

Kirchheimer, M. (2011), "Problemas de lectura: lo infantil y lo adulto en la animación comercial contemporánea”, Oficios Terrestres, $\mathrm{N}^{\circ} 27$, pp. 1-29.

Laferla, J. (2013), "Cine expandido, o el cine después del cine”, en Piñón, J.F. (coord.), Cuadernos de politicas culturales. Indicadores culturales 2012, EDUNTREF, Buenos Aires.

Landi, O., Vacchieri, A. y Quevedo, L.A. (1990), Públicos y consumos de Buenos Aires. Documento del Centro de Estudios Sociales, $N^{\circ} 32$, CEDES, Buenos Aires.

Marino, S. (2013), "Espacio audiovisual argentino: claroscuros de un presente exitoso y un futuro incierto", Austral Comunicación, No 2 (2), pp. 187-202.

Moguillansky, M. (2007), El cine en la ciudad de Buenos Aires en un contexto de transformaciones globales, en AA.VV., Las industrias culturales en la ciudad de Buenos Aires, Gobierno de la Ciudad de Buenos Aires, Observatorio de las Industrias Culturales (OIC), Buenos Aires, pp. 83-113.

- (2008), "La circulación de cine brasileño en Argentina: el (corto) circuito comercial", en V Jornadas de Sociología de la Universidad Nacional de La Plata. Recuperado de http://www.aacademica.com/000-096/200.pdf.

- (2009), "Políticas de la crítica y críticas políticas", en XXVII Congreso de la Asociación Latinoamericana de Sociología, Buenos Aires. Recuperado de http://www.aacademica.com/000-062/215.pdf.

- (2011), La imaginación en cuestión. El cine brasileño en la Argentina desde la creación del MERCOSUR (1995-2005), EAE, Berlín.

Perelman, P. y SeIvach, P. (2005), La industria cinematográfica en la Argentina: Entre los limites del mercado y el fomento estatal, CEDEM-GCBA, Buenos Aires. 
Pujol, S. (1989), "Los porteños y el cine mudo: un amor a primera vista", Todo es historia, $\mathrm{N}^{\circ} 259$, pp. 52.

Quintar, A. y Borello, J.(2011), “Consumos culturales en Argentina: el caso del cine en la población de estudiantes universitarios", en XXVIII Congreso ALAS, Recife. Recuperado de http://www.ungs.edu.ar/ms_ico/wp-content/ uploads/2012/03/Quintar-Borello-Consumo-de-cine.pdf.

- (2014a), "Evolución histórica de la exhibición y el consumo de cine en Buenos Aires”, Revista H-Industri@, No 14, pp. 81-120.

- (2014b), "Consumos culturales en Argentina: El caso del cine en la población de estudiantes universitarios", Imagofagia, No 9 . Recuperado de http://www. asaeca.org/imagofagia/index.php?option=com_content\&view=article\&id=3 95: consumos-culturales-en-argentina-el-caso-del-cine-en-la-poblacion-deestudiantes-universitarios \&catid=54: numero-9 $\&$ Itemid $=165$.

Russo, E. (2012), "El 3D una vez más. ¿Esta vez sí? El cine en relieve ante los espectadores contemporáneos", Cuaderno. Centro de Estudios en Diseño y Comunicación, No 39, pp. 269-281.

Samaja, J. (2006), "Recepción en Argentina del espectáculo cinematográfico audiovisual (1929-1933)", Revista Argentina de Investigación Cinematográfica, $\mathrm{N}^{\circ}$ 1. Recuperado de http://www.sai.com.ar/cine/raic/raic_v1_n1_00.html.

Schmucler, H. y Terrero, P. (1992), "Nuevas Tecnologías y transformación del Espacio Público. Buenos Aires 1970-1990”, Telos, N³2. Recuperado de http://telos.fundaciontelefonica.com/telos/anteriores/num_032/opi_perspectivas3.html.

Serra, M.S. (2011), Cine, escuela y discurso pedagógico. Articulaciones, inclusiones y objeciones en el siglo XX en Argentina, Teseo, Buenos Aires.

Terrero, P. (1999), "Ocio, prácticas y consumos culturales. Aproximación a su estudio en la sociedad mediatizada”, en Sunkel, G., El consumo cultural en América Latina. Construcción teórica y líneas de investigación, Convenio Andrés Bello, Bogotá, pp. 196-213.

Torterola, E.(2009), "El nuevo cine argentino en la encrucijada actual. Desequilibrios y desafíos en la industria cinematográfica nacional”, en AMATRIAIN, I. (coord.), Una década de nuevo cine argentino. Industria, crítica, formación y estéticas cinematográficas, CICCUS, Buenos Aires, pp. 191-206.

- (2010), "El cine y la ciudad en el cambio de siglo. Apuntes sobre las transformaciones recientes en el consumo audiovisual en Buenos Aires", Miríada, No 5, pp. 103-132. 
Velleggia, S. (2009), "De la subversión de la mirada a las pantallas de la era digital: los nuevos imaginarios", en Primer Congreso Iberoamericano de Cultura: cine y audiovisual en Iberoamérica, pp. 124-133. Recuperado de http://www.untref.edu.ar/documentos/indicadores2008/De\%20la\%20 subversion $\% 20 \mathrm{de} \% 20 \mathrm{la} \% 20$ mirada $\% 20 \mathrm{a} \% 20$ las $\% 20$ pantallas $\% 20 \mathrm{de} \% 20$ la $\% 20$ era $\% 20$ digital $\% 20 \operatorname{los} \% 20$ nuevos $\% 20$ imaginarios $\% 20$ Susana $\% 20$ Vellegia.pdf.

Vidal, A. (1990), Viendo video. Pautas de consumo de un nuevo medio, CEUR, Buenos Aires.

Wolf, S. (1996), El periodismo cinematográfico: construcción de los públicos cinematográficos en la década del 20, Tesina de Licenciatura, FCS-Universidad de Buenos Aires.

Wortman, A. (2002), "Identidades sociales y consumos culturales: el consumo de cine en la Argentina”, en Intersecciones en Comunicación, $N^{\circ} 2$, pp. 13-31.

- (2003), Pensar las clases medias. Consumos culturales y estilos de vida urbana en la Argentina de los noventa, La Crujía, Buenos Aires.

- (2009), "Consumo de cine en la Argentina. ¿Es posible reinventar los imaginarios sociales?", en Primer Congreso Iberoamericano de Cultura: cine y audiovisual en Iberoamérica, pp. 104-113. Recuperado de http://www.untref.edu. ar/documentos/indicadores2008/Consumo\%20de\%20cine $\% 20$ en $\% 20 \mathrm{Ar}$ gentina $\% 20$ Es $\% 20$ posible $\% 20$ reinventar $\% 20$ los $\% 20$ imaginarios $\% 20$ sociales\%20Ana\%20Wortman.pdf.

Teatro

Beaulieu, P. (2007), “¿Quién Asiste al Teatro? Investigación sobre consumo cultural de Teatro Independiente en la ciudad de Córdoba”, El Apuntador, Córdoba.

- (2009), "Estudio de caso. Oferta y consumo en el teatro independiente de la ciudad de Córdoba”, en Getino, O. (coord.), Indicadores culturales 2009, pp. 126-132. Recuperado de http://www.untref.edu.ar/documentos/indicadores_culturales/2009/Empleo\%20-\%20Paula\%20Beaulieu. pdf.

Cerdeira, M. y Sánchez Salinas, R. (2008), "Estudio Nacional de Público Teatral”. Recuperado de http://www.inteatro.gov.ar/2008/estadisticas.php. 
Fernández, A. (2013), "El público formoseño de teatro: motivaciones y percepciones", en II Jornadas Cientificas para Jóvenes Investigadores, Formosa, 29 y 30 de agosto.

Frega, G., Brizuela, M., Yukelson, A. y otros (2004), El teatro de Córdoba (1900-1930): documentación y crítica, Grupo de Estudios del teatro cordobés, Córdoba.

\section{Danza y festivales}

Gimeno, D. (2012), "Fiesta Nacional del Sol. Las imbricadas relaciones entre lo popular/masivo y la cultura dominante", en XVI Jornada Nacionales de Investigadores en Comunicación. Recuperado de http://sm000153.ferozo. com/memorias/pdf/gijornadasdeinvestigacion_danielgimeno.pdf.

GuZmán, J.A. (2010a), "Baile: entre la manifestación ritual y la experiencia estética”, en García Vargas, A. (comp.), Ciudad. San Salvador de Jujuy como texto (pp. 189-198), EDIUNJu, San Salvador de Jujuy.

- (2010b) "Fiesta en la calle. Comunicación, cultura e identidad en el corso jujeño”, en García Vargas, A. (ed.), Ciudad. San Salvador de Jujuy como texto, EDIUNJu, San Salvador de Jujuy, pp. 105-111.

Música y baile

Alabarces, P. (1993), Entre Gatos y Violadores: el rock nacional en la cultura argentina, Colihue, Buenos Aires.

- (2009), "Gustavo Blázquez: Músicos, mujeres y algo para tomar. Los mundos de los cuartetos de Córdoba”, Trans. Revista transcultural de música, $\mathrm{N}^{\circ} 13$, pp. 1-3.

Alabarces, P. y Rodríguez, M.G. (comps.) (2008), Resistencias y mediaciones. Estudios sobre cultura popular, Paidós, Buenos Aires.

Alabarces, P. y Varela, M. (1988), Revolución, mi amor. El rock nacional 19651976, Biblos, Buenos Aires.

Alabarces, P., Salerno, D., Silba, M. y Spataro, C. (2008), "Música popular y resistencia: los significados del rock y la cumbia”, en Alabarces, P. y RodríGUEZ, M.G. (comps.), Resistencias y mediaciones. Estudios sobre cultura popular, Paidós, Buenos Aires, pp. 31-58. 
Aliano, N. (2010), "Culturas populares: Orientaciones y perspectivas a partir del análisis de un campo de estudios", Sociohistórica, No 27, pp. 185-209.

Aliano, N., López, M., Pinedo, J., Stefoni, A. y Welschinger, N. (2010), "Banderas en tu corazón. Narrativas identitarias, vida cotidiana y prácticas de apropiación de la música rock en los sectores populares contemporáneos”, Cuestiones de Sociología No 5-6, pp. 165-184.

Benedetti, C. (2008), "El rock de los desangelados. Música, sectores populares y procesos de consumo", Trans. Revista Transcultural de Música, № 12.

Blázquez, G. (2008a), "Cuarteteros y electrónicos: subjetividades juveniles y consumos musicales", en Da Porta, E. y SAur, D. (coord.), Giros teóricos en las ciencias sociales y humanidades, Comunicarte, Córdoba, pp. 99-106.

- (2008b), Músicos, mujeres y algo para tomar. Los mundos de los cuartetos en Córdoba, Recovecos, Córdoba.

- (2011), "Hacer belleza. Género, raza y clase en la noche de la ciudad de Córdoba”, Astrolabio, N 6, pp. 127-157.

- (2012a), "I feel love". Performance y performatividad en la pista de baile, en Citro, S. y Ascheri, P. (coord.), Cuerpos en movimiento. Antropología de y desde las danzas, Biblos, Buenos Aires, pp. 291-306.

- (2012b), "Masculinidades cool. Hacer género y clase en los clubs electrónicos”, Estudios, N ${ }^{\circ} 27$, pp. 45-57.

Bustos Castro, P. (1994), "Rocanrol. El recital: los militantes del bardo", en Miguez, D. y Semán, P. (eds.), Entre santos, cumbias y piquetes, Biblos, Buenos Aires, pp. 51-76.

Citro, S. (2000), "El análisis del cuerpo en contextos festivo-rituales: el caso del pogo", Cuadernos de Antropología, Social, No 12, pp. 225-242.

- (2005), "Ritual y espectáculo en la música indígena: El caso de los jóvenes toba del Chaco argentino", Latin American Music Review - Revista de Música Latinoamericana, $\mathrm{N}^{\circ} 26$, pp. 318-346.

- (2006), "El análisis de las performances: Las transformaciones de los cantosdanzas de los toba orientales", en Schamber, P. y Wilde, G. (comp.), Simbolismo, ritual y performance, S/B, Buenos Aires, pp. 83-119.

- (2008), "El rock como ritual adolescente. Transgresión y realismo grotesco en los recitales de Bersuit", Trans. Revista Transcultural de Música, № 12 .

Citro, S. y Aschieri, P. (2012), Cuerpos en movimiento. Antropología de y desde las danzas, Biblos, Buenos Aires. 
Citro, S. y Cerletti, A. (2008), "Continuities and Re-elaborations in Indigenous Music and Dances: the Case of the Mocoví", Review: Literature and Arts of the Americas, $N^{\circ} 77$, pp. 271-275.

DíAz, C. (2000), "Cuerpo, ritual y sentido en el rock argentino. Un abordaje sociosemiótico", III Congreso IASPM-AL, Bogotá. Recuperado de http://www. iaspmal.net/wp-content/uploads/2011/10/Diazclaudio.pdf.

- (2009), Variaciones sobre el ser nacional. Una aproximación sociodiscursiva al folclore argentino, Recovecos, Córdoba.

Gallo, G. (2011), "Poder bailar lo que me pinta: movimientos libres, posibles y observados en pistas de baile electrónicas", en CAROzZI, M. J. (coord.), Las palabras y los pasos. Etnografías de la danza en la ciudad, Gorla, Buenos Aires, pp. 47-82.

Gallo, G. y Semán, P. (2009), "Superficies de placer: Sexo, religión y música electrónica en los pliegues de la transición 1990-2010”, Cuestiones de Sociología, No 5-6, pp. 123-142.

Garriga Zucal, J. (2008), "Ni "chetos" ni "negros": roqueros", Trans. Revista Transcultural de Música, $N^{\circ} 12$.

Kuasñosky, S. y Szulik, D. (1994), "Los extraños de pelo largo. Vida cotidiana y consumos culturales", en Margulis, M. (ed.), La cultura de la noche, Biblos, Buenos Aires, pp. 263-291.

Lenarduzzi, V. (2012), Placeres en movimiento. Cuerpo, música y baile en la "escena electrónica", Aidos editores, Buenos Aires.

Margulis, Mario (ed.) (1997), La cultura de la noche, Biblos, Buenos Aires.

Martín, E. (2008), "La cumbia villera y el fin de la cultura del trabajo en la Argentina de los 90", Trans. Revista Transcultural de Música, № 12.

- (2009), "Gilda no es ninguna santa: apuntes sobre las prácticas de sacralización de una cantante argentina”, Papeles de trabajo, N 5, pp. 1-14.

Míguez, D. (2006), "Estilos musicales y estamentos sociales. Cumbia, villa y transgresión en la periferia de Buenos Aires”, en Míguez, Daniel y Semán, PABlo (eds.), Entre santos, cumbias y piquetes. Las culturas populares en la Argentina reciente, Biblos, Buenos Aires, pp. 33-54.

Montes, M. de los Á. (2013), "Sobre la relación entre los espacios de escucha y el sentido otorgado a la música. El caso del tango en las milongas”, en VI Encuentro Panamericano de Comunicación. Recuperado de http://www.eci.unc. edu.ar/archivos/companam/ponencias/Recepci\%C3\%B3n\%20y\%20 apropiaci\%C3\%B3n\%20medi\%C3\%A1tica/-Unlicensed-Recepcion-yaporpiacion-mediatica-MONTES.pdf. 
Nieto Zuljevich Karaman, F. (2011), "Rock 2.0”, en Bianchi, M. y SandovaL, L. (eds.), en I Jornadas Patagónicas de estudios sociales sobre Internet y tecnologías de la comunicación, Universidad Nacional de la Patagonia San Juan Bosco, Comodoro Rivadavia. Recuperado de http://tecnologiaycultura. com.ar/actas2011/doc/m3nieto.pdf.

Orellana, V.M. (2013), "Mucho más que dos. Nuevas configuraciones en la "escena electrónica”" (reseña de Lenarduzzi, V., Placeres en movimiento. Cuerpo, música y baile en la "escena electrónica"), Astrolabio, № 10, pp. 546550 .

Pujol, S. (2007), "La anunciación del rock. Identidad, divino tesoro", Trampas de la comunicación y la cultura, $\mathrm{N}^{\circ}$ 52, pp. 14-20.

Salerno, D. (2008), "La autenticidad al palo: los modos de construcción de las alteridades rockeras", Oficios Terrestres, № 23, pp. 128-137.

Salerno, D. y Silba, M. (2006), "Juventud, identidad y experiencia: las construcciones identitarias populares urbanas", Question, No 10, pp. 1-10.

SEMÁn, P. (2006a), "Vida, apogeo y tormentos del "rock chabón"”, en Bajo continuo. Exploraciones descentradas sobre cultura popular y masiva, Gorla, Buenos Aires, pp. 61-77.

- (2006b), “El pentecostalismo y el 'rock chabón' en la transformación de la cultura popular”, en Míguez, D. y SEMán, P. (eds.), Entre santos, cumbias y piquetes. Las culturas populares en la Argentina reciente, Biblos, Buenos Aires, pp. 215-240.

Semán, P. y Vila, P. (2008), "La música y los jóvenes de los sectores populares: más allá de las 'tribus'", Trans. Revista Transcultural de Música, $N^{\circ} 12$.

Silba, M. (2010), "La cumbia en la Argentina. Origen social, públicos populares y difusión masiva”, en Semán, P. y Vila, P. (comps.), Cumbia. Raza, nación, etnia y género en Latinoamérica, Gorla, Buenos Aires, pp. 247-296.

Ugarte, M. (2008), "Música: Tecnología, usos y consumos en una industria de relaciones asimétricas", en Ugarte, M. y Sanjurjo, L. (eds.), Emergencias: Cultura, música y política, Ediciones del Centro Cultural de la Cooperación Floreal Gorini, Buenos Aires.

Vigliotta, M. (2011), “Tales cuerpos, tales rockeros”, en 1er. encuentro sobre Juventud, medios de comunicación e Industrias culturales, La Plata. Recuperado de http://www.perio.unlp.edu.ar/observatoriodejovenes/sites/perio.unlp. edu.ar.observatoriodejovenes/files/vigliota.pdf. 
- (2013), "A la carga mi rocanrol: repensando algunos conceptos en el análisis de los conciertos de rock", La revista del CCC, $N^{\circ} 17$. Recuperado de http:// www.centrocultural.coop/revista/articulo/389/.

Vila, P. (1985), "Rock Nacional. Crónicas de la resistencia juvenil”, en Jelin, E. (ed.), Los nuevos movimientos sociales, CEAL, Buenos Aires, pp. 87-147.

- (1996), "Identidades narrativas y música. Una primera propuesta para entender sus relaciones", Trans. Revista Transcultural de Música, № 2 .

Welschinger Lascano, N., Aliano, N., López, M. y Pinedo, J. (2011), "Del recital a las tramas cotidianas. Sensibilidades, identificaciones y prácticas de escucha de jóvenes (y no tan jóvenes) seguidores de 'El Indio Solari’”, Revista Argentina de Estudios de Juventud, № 4. Recuperado de http://perio.unlp. edu.ar/ojs/index.php/revistadejuventud/article/view/1493/1266.

Wortman, A. (2001), "Aproximaciones conceptuales y empíricas para abordar identidades sociales juveniles y consumos culturales en la sociedad argentina del ajuste", Documentos de trabajo, $\mathrm{N}^{\circ} 24$, Instituto de Investigaciones Gino Germani, Buenos Aires.

Casos marginales

Beltramino, F. (2003), "La relación del público con la música electroacústica”, Documentos de jóvenes investigadores, $\mathrm{N}^{\circ} 3$, Instituto de Investigaciones Gino Germani, Buenos Aires.

- (2010), "Abordajes de la relación arte/sociedad: ¿sociología del arte, estética sociológica o qué?”, en III Jornadas Latinoamericanas de Artes Integradas, Universidad Nacional de Lanús. Recuperado de http://beltraminofabian. blogspot.com.ar/2010_10_01_archive.html.

Benzecry, C. (2012), El fanático de la ópera, Siglo XXI, Buenos Aires. 